\title{
Geographical Frame of Reference and Dangerous Intergroup Attitudes: A Double-Minority Study in Sri Lanka
}

\author{
Mark Schaller \\ University of British Columbia
}

A. M. N. D. Abeysinghe
University of Peradeniya

An ethnic group can comprise a local majority, but be a minority within a broader geographic region or vice-versa. This situation has interesting psychological implications that may contribute to intergroup conflict. To test some of these implications, an experiment was conducted in Sri Lanka, during a ceasefire in the conflict between the government and Tamil rebellion forces. Participants were 100 Sinhalese students. An experimental manipulation was introduced to make one of two geographical regions salient: either just Sri Lanka (within which Sinhalese outnumber Tamils) or a broader region of south Asia (within which Sinhalese are outnumbered by Tamils). Following the manipulation, stereotypes and conflict-relevant attitudes were assessed. Results revealed that when Sinhalese participants were inclined to think of their group as the outnumbered minority, stereotypic perceptions of Tamils were more demonizing (i.e., depicting Tamils as more malevolent and also more competent), and their conflict-relevant attitudes were less conciliatory. These results have conceptual implications as well as implications for understanding conflict and conflict resolution.

KEY WORDS: Conflict, Distrust, Double-Minority, Geography, Political attitudes, Stereotypes

In Leviathan, Thomas Hobbes (1651/1998) famously identified "diffidence"-in its original meaning of distrust in the dispositions of others-as one of the principal causes of quarrel and conflict. Plenty of research bears this out. Distrust leads to competitive behavior in mixed-motive experimental games (Insko \& Schopler, 1998) and contributes to aggressive acts such as bullying and gang violence (Decker \& Van Winkle, 1996; Dodge, 1980). Distrust in others' inten- 
tions is implicated as a causal factor in studies of tribal warfare in small-scale societies (Chagnon, 1992), and in analyses of major civil and international wars (Chirot, 2001; Robarcheck, 1990; Vasquez, 1992). Not only does fear of being victimized by a malevolent outgroup serve as a justification and a trigger for acts of violence launched against that outgroup, but it may also serve as a serious impediment to peacemaking and conflict resolution (Bar-Tal, 2000, 2001). In general, mutual distrust between groups appears to be one of the most problematic psychological elements of any conflict situation.

Under what sorts of conditions might mutual distrust be most likely to emerge? There are many answers to this question, some of which have received extensive research inquiry. This article focuses on a situation that is sometimes noted in discussions of real-world conflict, but which has not yet received sustained empirical attention. This situation arises under demographic circumstances in which each group perceives itself to be a minority group.

\section{Double Minorities and Intergroup Conflict}

Within any given population, the sizes of different subpopulations inevitably differ; consequently, it is usually easy to identify one group that is a majority group relative to another. Within the borders of Israel, Jews greatly outnumber Arabs. Within Sri Lanka, Sinhalese greatly outnumber Tamils. How is it possible, then, that everyone might perceive their own group to be in the minority? The answer has to do with the perceiver's geographical frame of reference. Jews greatly outnumber Arabs within Israel; but within the broader geographical sphere of the Middle East, Arabs greatly outnumber Jews. Sinhalese greatly outnumber Tamils within Sri Lanka, but within the broader geographical sphere of southern Asia, Tamils greatly outnumber Sinhalese. These are just two of many such cases.

This particular situation offers one example of the broader set of structural contexts that create "double asymmetries" in power relations (Rouhana \& Bar-Tal, 1998; Rouhana \& Fiske, 1995)—contexts in which, from one frame of reference, the perceived balance of power is tilted in favor of one particular group over another; but from another frame of reference, the perceived balance of power is reversed. This particular form of power asymmetry might more specifically be considered one of "double minorities," where each group can justifiably feel outnumbered by some other group, depending on the geographical frame of reference.

The implications of the double minority situation become apparent when we consider some of the psychological consequences of being in a group that is outnumbered. Members of relatively smaller groups show relatively greater concern for the "groupness" of groups (Brewer, Weber, \& Carini, 1995; Simon \& Hamilton, 1994) and show greater favoritism for their ingroup over an outgoup (Mullen, Brown, \& Smith, 1992). These sorts of experimental results are consistent with predictions derived from psychological theories of social identity (e.g., 
Brewer, 1999; Tajfel \& Turner, 1986): Minority status enhances the salience of and concern for one's own group identity and compels individuals to promote the merit of their ingroups-sometimes at the expense of devaluing outgroups as well.

Of course, the perception of being outnumbered not only arouses concerns with social identity; it also arouses feelings of vulnerability to danger. This sense of vulnerability appears to be a very basic and highly automatized psychological consequence, indicated by the fact that relatively smaller group size compels individuals of many animal species_including humans - to be hypervigilant to potential dangers (e.g., Roberts, 1996; Wirtz \& Wawra, 1986). The link between minority status and a sense of vulnerability seems especially likely within intergroup contexts defined by a history of actual conflict.

Vulnerability to danger has predictable consequences on stereotypic perceptions of others. When individuals feel vulnerable, stereotypes linking outgroups to threat-relevant traits are especially likely to come to mind. In one study, for example, Canadians who chronically believed the world to be a dangerous place and who were temporarily in the dark (an environmental condition connoting vulnerability) were especially likely to perceive Iraqis to be hostile and untrustworthy (Schaller, Park, \& Faulkner, 2003). Thus, if indeed members of outnumbered groups feel more vulnerable to danger, they are also more likely to perceive outgroups as having malevolent intentions. These kinds of stereotypic perceptions can have nontrivial consequences on judgments and behavior within conflict situations.

These psychological consequences of minority status are problematic enough when just one group is cast as the threatened minority; the problems are magnified in the double-minority context. In such cases all members of the population, regardless of their actual group membership, may perceive themselves to be in a threatened minority group. As a consequence, each group may perceive the other to be especially malevolent and untrustworthy, may feel especially justified in the use of violence against the other, and may be especially wary of negotiated attempts at conflict resolution.

These sorts of considerations have led scholars to discuss the role of doubleminority demographics in specific cases of intergroup conflict (e.g., Eidelson \& Eidelson, 2003; Ross, 1995). But, as yet, these speculations have not been buttressed by rigorous empirical inquiry. There has been virtually no research directly exploring the psychological implications of double-minority situations in the real world.

\section{Geographical Frame of Reference}

Implicit in our discussion of the double-minority situation is the fact that individuals have the opportunity to perceive their ingroup either as a majority, or as an outnumbered minority group. The "choice" depends on their geographical frame of reference. A Palestinian might one moment have her attention drawn to 
the large population of Arabic peoples in the Middle East, but a moment later be reminded that Palestinians are vastly outnumbered within the borders of Israel. Within Sri Lanka, Sinhalese might sometimes focus on the fact that theirs is the most numerous ethnic group in the country, but at other times be highly aware that they are outnumbered by Tamils within the broader geographical region. These shifts in frame of reference may have immediate psychological consequences. When the frame of reference compels individuals to feel that their group is outnumbered, they may perceive an outgroup to be especially malevolent. When the frame of reference compels individuals to feel that their group is the majority, they may judge the outgroup to pose less of a threat. These shifting perceptions may have additional consequences on other attitudes pertaining to the outgroup and - in cases of ongoing conflict—on attitudes toward that conflict and its potential resolution.

To our knowledge, there is no prior research testing hypotheses about the consequences of geographical frame of reference on intergroup attitudes within double-minority situations. The study reported here represents one attempt to do so. This research was conducted in Sri Lanka.

\section{Double Minorities and Ethnic Conflict in Sri Lanka}

Of the nearly 20 million people in Sri Lanka, approximately $74 \%$ are Sinhalese. There are several additional ethnic populations within Sri Lanka, the most numerous of which are Tamils (18\% of the nation's population). Thus, within the borders of Sri Lanka, Sinhalese represent a clear majority, and Tamils are vastly outnumbered. ${ }^{1}$

There are very few Sinhalese people outside the boundaries of Sri Lanka. In contrast, there are tens of millions of Tamils elsewhere. Over 60 million people live in the southern Indian state of Tamil Nadu, for instance, virtually all of whom are Tamil. Thus, while Sinhalese outnumber Tamils within Sri Lanka, Sinhalese are vastly outnumbered by Tamils within the Indian subcontinent.

These demographic facts create a classic double-minority situation. Tamils are keenly aware of their relatively small numbers within Sri Lanka. Sinhalese are keenly aware of their relatively small numbers within the broader geographical region.

There has been conflict between Sinhalese and Tamils for decades, and ongoing military violence since the early 1980s (for a brief overview, see Rogers,

\footnotetext{
${ }^{1}$ There are two distinct subpopulations of Tamils in Sri Lanka. The larger subpopulation has been associated with Sri Lanka for centuries and predominantly populates the northern and eastern coastal regions of the island. These are sometimes referred to as "Sri Lankan Tamils" or "Jaffna Tamils." An additional, smaller subpopulation of Tamils is comprised of descendants of nineteenth-century migrants from India, brought forcibly to work on colonial coffee and tea planting estates in the central hill regions of the island. These are sometimes referred to as "Indian Tamils" or "Estate Tamils." The ethnic conflict in Sri Lanka primarily involves the Sri Lankan Tamils.
} 
Spencer, \& Uyangoda, 1998). Since the mid-1980s, a militant Tamil Organization - the Liberation Tigers for Tamil Eelam (LTTE)—has fought a political, military, and terrorist campaign for a sovereign Tamil state (Eelam) occupying the northern and eastern regions of the island. The predominantly Sinhalese Sri Lankan government has deployed its military in an attempt to defeat this LTTE campaign. The conflict and its consequences have fundamentally shaped life in Sri Lanka for over two decades.

A fragile ceasefire went into effect at the beginning of 2002, along with a complicated, slow-moving set of negotiations designed to explore means toward achieving a permanent solution to the conflict. This peace process was ongoing at the time that the current research was conducted, in 2003.

\section{Overview of the Research}

The sociopolitical situation in Sri Lanka provided an excellent opportunity to test the effects of individuals' geographical frame of reference on group stereotypes and conflict-relevant attitudes. The study was conducted on a sample of Sinhalese students. Experimental methods were used to make one of two geographical regions temporarily salient. In one condition, a geographic task was used to focus participants' attention on Sri Lanka (within which Sinhalese outnumber Tamils). In the other condition, the geographic task focused participants' attention on a broader region of southern Asia (within which Sinhalese are outnumbered by Tamils).

Following this manipulation, participants completed a questionnaire designed to assess several attitudes relevant to the Tamil-Sinhalese conflict and its potential resolution.

Participants also completed an additional questionnaire assessing the extent to which various traits were stereotypically characteristic of either the Tamils or Sinhalese. Included on this questionnaire were several traits assessing malevolence, as well as additional traits that tap into the separate personality dimension of capability or "agency." (For more information on these two key dimensions underlying group stereotypes, see Fiske, Cuddy, Glick, \& Xu, 2002.) To the extent that geographical frame of reference influences feelings of vulnerability to outgroup threat, then the map manipulation may not only affect perceptions of harmful intent (malevolence), but also perceived ability to carry out that intent (agency). Of primary conceptual interest were the effects of the map manipulation on perceived stereotypes of the outgroup (Tamils); we explored possible effects on Sinhalese stereotypes as well.

Given these methods, the results test hypotheses about the effects of geographical frame of reference on cognitively accessible outgroup stereotypes and on attitudes relevant to intergroup conflict. In addition to testing the effects of geographical frame of reference specifically, these results also speak to broader questions about the psychology of minority groups (e.g., Mullen, 1991; Simon, 1998) and the bases of intergroup prejudice. 


\section{Methods}

\section{Design}

The experiment contained two manipulated variables. One variable was created through a map manipulation embedded within a geography task: Some participants were presented with a map of Sri Lanka; other participants were presented with a map that depicted not only Sri Lanka but most of India as well. The second variable was introduced in the context of a questionnaire assessing impressions of cultural stereotypes: Some participants rated stereotypes of Tamils; others rated stereotypes of Sinhalese. These two variables were crossed in a $2 \times 2$ factorial design.

\section{Participants}

Participants were 100 Sinhalese high-school students (57 female, 43 male) from central Sri Lanka, between the ages of 15 and 18. (The vast majority of Sri Lankans attain both a primary and secondary education. Thus, on many demographic characteristics, high school students are fairly representative of the broader Sinhalese population.) They participated voluntarily as part of a special classroom exercise conducted by a visitor to their classroom and were assured that their responses would remain anonymous and confidential. The experiment was conducted in four separate sessions, with 25 participants in each session. All participants in each session received the same materials and instructions; a random assignment procedure was used to assign experimental conditions to sessions.

\section{Procedure}

The experimental materials were printed in Sinhala, and the experimental session was conducted in Sinhala by a Sinhalese experimenter. Because participants were generally unfamiliar with the kinds of rating scales used in the study, the experimenter reiterated and clarified instructions that appeared on the printed materials.

Geography Task (Map Manipulation). The session began with a task ostensibly designed to assess participants' knowledge of geography. Participants were presented with a sheet of paper on which was printed a map depicting the contours of a familiar land mass. The specific map differed across two experimental conditions. Half of the participants were presented with a map showing just the outline of Sri Lanka. The other 50 participants were presented with a map that depicted not only Sri Lanka but most of India as well. (This map portrayed all of India south of the 30th parallel and west of Bangladesh. This included-but was not limited to- - the region in southern India that is heavily populated by Tamils.) Both maps indicated, with black dots, the location of 10 unlabelled cities; a list of city names 
was presented separately. (In the Sri Lanka Map condition, all 10 cities were located in Sri Lanka; in the India Map condition, eight of the 10 cities were located in India. Regardless of condition, exactly one of the 10 cities was located in the disputed Tamil Eelam region of Sri Lanka.) Participants in both conditions were asked to locate the cities on the map by writing in the city name by the appropriate dot. After they had finished marking the map, participants were asked to roughly estimate the ethnic breakdown of the people living in the area depicted on the map. They did so by writing in a percentage estimate next to 6 different ethnic categories listed at the bottom of map: Sinhalese, Tamils, Muslims, Europeans, Burghers, and Sikhs. (No constraints were placed on these percentage estimates; for instance, participants were not instructed to ensure that these estimates added up to $100 \%$.) Of particular interest as a check on the manipulation was the estimated percentage of Sinhalese, relative to Tamils.

Sociopolitical Attitudes. After participants had completed the geography task, they were given a questionnaire assessing their attitudes toward five social/ political issues. One item pertained to the promotion of birth control methods in Sri Lanka and was not relevant to the Sinhalese-Tamil conflict. The remaining four items were conflict-relevant. The first of these items simply inquired into participants' attitude toward the ongoing peace process. The second item assessed their support for the establishment of an independent, sovereign state of Tamil Eelam. The third item assessed their support for the establishment of a semi-independent Eelam state. The final item assessed support for a recent tendency-within Sri Lankan political and media circles - to show linguistic courtesy toward the LTTE leader via the use of an honorific title connoting respect. Responses to all attitude items were recorded on 10-point scales with the endpoints (1 and 10) marked "strongly disagree" and "strongly agree."

Stereotypes. On a final questionnaire, participants were given a list of 21 personal characteristics and were asked to indicate the extent to which each characteristic was part of the cultural stereotype of a specific ethnic group. Half the participants were asked to rate the stereotype of Tamils. The other 50 participants were asked to rate the stereotype of Sinhalese. Regardless of which ethnic group they were asked to consider, instructions made clear that participants were not to indicate their own personal impressions of the ethnic group, but rather were to indicate their perceptions of prevailing society-wide stereotypes of that ethnic group. (Similar procedures have been used in previous research to assess ethnic stereotypes that—regardless of respondents' personal beliefs — are highly accessible in working memory; e.g., Devine \& Elliot, 1995.)

The 21 characteristics on the questionnaire were, in order: (1) Loves own ethnic group, (2) Poor, (3) Hardworking, (4) Cunning, (5) Foolish, (6) Peace lovers, (7) Hostile, (8) Inhuman, (9) Selfish, (10) Nä̈ve, (11) Unclean, (12) Terrorist or supporters of terrorism, (13) Unpleasant way of speech, (14) Aggressive, (15) Anger towards [outgroup: Tamil/Sinhalese] people, (16) Lazy, (17) Greedy for money, (18) Religious, (19) Fights for own rights, (20) Helpless, and (21) 
Strong ingroup unity. ${ }^{2}$ From this complete set of ratings, we attempted to derive composite measures of malevolence and agency - the two dimensions that are fundamental to so many stereotypes (Fiske et al., 2002), and especially pertinent to intergroup conflict. We judged that seven of these characteristics indicated malevolence: (Items 4, 6, 7, 8, 12, 14, 15; ratings on Item 6 were reverse-scored), and that three additional characteristics indicated agency (Items 10, 19, and 20; ratings on Items 10 and 20 were reverse-scored). Composite indices were computed for both malevolence and agency. (For the Malevolence index, mean interitem $r=.35$ and Cronbach's alpha $=.80$. For the Agency index, mean interitem $r=.23$ and Cronbach's alpha $=.47$.) These indices were the primary focus of the analyses presented below.

\section{Results}

\section{Manipulation Check}

The purpose of the map manipulation was to make salient a geographical context in which participants' ingroup was either in the majority (Sri Lanka Map condition), or the minority (India Map condition). The estimated percentages of Sinhalese (relative to Tamils) provide a check on this manipulation. Results revealed that the estimated percentage of Tamils was similar across the two conditions ( $M$ s of 40.23 and 44.26), but the estimated percentage of Sinhalese differed greatly: $M=72.79$ in the Sri Lanka Map condition and $M=28.10$ in the India Map condition, $t(98)=10.95, p<.001$.

Therefore, consistent with the intent of the manipulation, participants in the Sri Lanka Map condition perceived their ingroup to outnumber Tamils (within Sri Lanka), whereas participants in the India Map condition perceived their ingroup to be outnumbered by Tamils (within the broader geographical region). This effect is substantiated by a statistical interaction, from a repeated measures ANOVA, between the map manipulation and the two percentage estimates, $F(1,98)=94.21$, $p<.001 .^{3}$

\footnotetext{
${ }^{2}$ These characteristics were selected based on the results of a separate investigation into the contents of stereotypes about various ethnic groups in Sri Lanka. The 21 characteristics included in this questionnaire had been found to be central to the stereotypes of one or more of the following ethnic groups: Sinhalese (e.g., Selfish, Foolish), Sri Lankan Tamils (e.g., Loves own ethnic group, Terrorist or supporters of terrorism), Indian Tamils (e.g., Poor, Nä̈ve), and Muslims (Religious, Cunning).

${ }^{3}$ Some readers may wonder about the accuracy of participants' estimates. With only one exception, the mean percentage estimates were not accurate at all. The one exception was this: Participants were generally accurate in estimating the percentage of Sri Lankans who are Sinhalese. Most other estimates were substantially inflated (e.g., the mean estimated percentages of Tamils in both the Sri Lanka and India Map conditions are gross overestimations); for most participants, the total of the percentage estimates exceeded $100 \%$, often by a substantial amount. These patterns of accuracy and inaccuracy may reflect the sorts of demographic facts that are and are not emphasized in Sinhalese schools, as well as the unconstrained nature of the task and the difficulty that most people have in
} 
Table 1. Impact of Map Manipulation on Sociopolitical Attitudes

\begin{tabular}{lcccccc}
\hline Attitude Item & \multicolumn{2}{c}{ Map Condition } & $\mathrm{r}$ & $\mathrm{t}$ & $\mathrm{p}$ \\
\cline { 2 - 5 } & Sri Lanka & India & & & & \\
\hline Support for ongoing peace process & 9.50 & 8.58 & .22 & 2.24 & .028 \\
& $(1.18)$ & $(2.68)$ & & & \\
Support for sovereign state of Tamil Eelam & 4.64 & 2.04 & .46 & 5.13 & .001 \\
Support for semi-independent state of Tamil Eelam & $(3.17)$ & $(1.61)$ & & & \\
& 5.30 & 3.94 & .21 & 2.17 & .033 \\
Support for linguistic courtesy toward L.T.T.E. leader & $(3.36)$ & $(2.90)$ & & & \\
& $(3.24$ & 2.60 & .10 & 1.03 & .307 \\
\hline
\end{tabular}

Notes. Responses on attitude items were recorded on a scale of 1 to 10 , with higher values indicating greater support. Standard deviations are in parentheses below each mean. Values indicated under "r" indicate the size of the effect of the map manipulation, calculated using the formula for $r_{\text {equivalent }}$ (Rosnow \& Rosenthal, 2003).

\section{Sociopolitical Attitudes}

Four of the sociopolitical attitude items had some clear relevance to the Sinhalese-Tamil conflict. (These items were largely uncorrelated with each other and so were analyzed separately.) The map manipulation exerted a substantial impact on three of these four items. For a summary of descriptive and inferential statistics, see Table 1.

Compared to participants in the Sri Lanka Map condition, those in the India Map condition were less favorable toward a sovereign Eelam state $(p<.001)$, less favorable toward a semi-independent Eelam state $(\mathrm{p}=.033)$, and also had a less favorable attitude toward the ongoing peace process $(\mathrm{p}=.028)$.

\section{Perceived Stereotypes}

Of particular interest was the effect of the map manipulation on stereotypes connoting malevolence and agency. Consequently, statistical analyses focused on the two composite indices. Results on each index were analyzed within a $2 \times 2$ ANOVA, allowing us to assess main effects and interaction effects due to the map manipulation (Sri Lanka map or India map) and the target group rated (Sinhalese or Tamils). In addition, given that the conceptual hypotheses pertain primarily to stereotypes about Tamils, we also report statistical analyses explicitly testing the effects of the map manipulation on stereotypes about Tamils and Sinhalese separately.

thinking about percentages rather than frequencies (Gigerenzer, 1998). In any case, for the purposes of the present investigation, the actual percentage estimates are of less conceptual interest than the relative estimates of Sinhalese and Tamils. 
Table 2. Impact of Map Manipulation on Perceived Stereotypes

\begin{tabular}{llccccc}
\hline Stereotype Index & Group Rated & \multicolumn{2}{c}{ Map Condition } & $\mathrm{r}$ & $\mathrm{t}$ & $\mathrm{p}$ \\
\cline { 3 - 5 } & & Sri Lanka & India & & & \\
\hline Malevolence & Tamils & 4.22 & 5.71 & .32 & 2.37 & .022 \\
\multirow{2}{*}{ Malevolence } & Sinhalese & 3.48 & $(1.84)$ & & & \\
& & $(1.71)$ & $(1.37)$ & .03 & 0.24 & .899 \\
Agency & Tamils & 4.65 & 6.72 & .48 & 3.76 & .001 \\
& & $(2.33)$ & $(1.45)$ & & & \\
Agency & Sinhalese & 4.89 & 6.07 & .33 & 2.39 & .021 \\
& & $(1.81)$ & $(1.66)$ & & & \\
\hline
\end{tabular}

Notes. Stereotype indices have a possible range from 1 to 10 , with higher values indicating greater stereotypicality. Standard deviations are in parentheses below each mean. Values indicated under " $r$ " indicate the size of the effect of the map manipulation, calculated using the formula for $\mathrm{r}_{\text {equivalent }}$ (Rosnow \& Rosenthal, 2003).

Results on the Malevolence Index are reported in the first two rows of Table 2. A $2 \times 2$ ANOVA on these means revealed main effects of the group rated (Tamils were rated as more malevolent than Sinhalese, $p<.001$ ) and the map manipulation (malevolence ratings were higher in the India map condition, $p=.040$ ), as well as a marginally significant interaction $(p=.074)$. Additional, more focused t-tests reveal more clearly that, compared to participants in the Sri Lanka Map condition, those in the India Map condition rated Tamils to be stereotypically more malevolent (effect size $r_{\text {equivalent }}=.32 ; p=.022$ ). No such effect was observed on ratings of Sinhalese.

Results on the Agency index are reported in the bottom half of Table 2 . A $2 \times 2$ ANOVA revealed only a main effect of the map manipulation (agency ratings were higher in the India map condition, $p<.001$ ). Additional, more focused t-tests reveal that, compared to participants in the Sri Lanka Map condition, those in the India Map condition rated Tamils to be stereotypically more agentic (effect size $\left.r_{\text {equivalent }}=.48 ; p<.001\right)$ and also rated Sinhalese to be stereotypically more agentic (effect size $r_{\text {equivalent }}=.33 ; p=.021$ ).

In addition to these primary analyses, ancillary exploratory analyses revealed a few additional effects of the map manipulation on other stereotype ratings. Among participants who rated Tamil stereotypes, those in the India Map condition gave higher ratings on the characteristics Lazy and Foolish, and lower ratings on the characteristics Loves own ethnic group and Religious; all p's $<.06$. Among participants who rated Sinhalese stereotypes, those in the India Map condition gave lower ratings on the characteristic Poor $(\mathrm{p}=.037)$.

\section{Mediation Analyses}

As hypothesized, the map manipulation had effects on political attitudes relevant to the Sinhalese-Tamil conflict, as well as on perceived stereotypes of 
Table 3. Mediation Results: Extent to Which Estimated Percentage of Sinhalese Mediated the Observed Effects of the Map Manipulation on Sociopolitical Attitudes and Stereotypes about Tamils

\begin{tabular}{|c|c|c|c|c|c|c|c|}
\hline \multirow[t]{2}{*}{ Dependent Variable } & \multirow[t]{2}{*}{ Predictor Variable } & \multicolumn{3}{|c|}{ One-Predictor Equation } & \multicolumn{3}{|c|}{ Two-Predictor Equation } \\
\hline & & B & beta & $\mathrm{p}$ & B & beta & $\mathrm{p}$ \\
\hline \multirow{2}{*}{$\begin{array}{l}\text { Support for ongoing } \\
\text { peace process }\end{array}$} & Map Condition & -.940 & -.220 & .028 & .400 & .080 & .576 \\
\hline & Percentage Estimate & - & - & - & .029 & .404 & .005 \\
\hline \multirow{2}{*}{$\begin{array}{l}\text { Support for sovereign } \\
\text { state of Tamil Eelam }\end{array}$} & Map Condition & -2.599 & -.462 & .001 & -2.37 & -.421 & .003 \\
\hline & Percentage Estimate & - & - & - & .005 & .013 & .700 \\
\hline \multirow{2}{*}{$\begin{array}{l}\text { Support for semi- } \\
\text { independent state }\end{array}$} & Map Condition & -.1 .360 & -.214 & .033 & .107 & .017 & .908 \\
\hline & Percentage Estimate & - & - & - & .033 & .311 & .034 \\
\hline \multirow{2}{*}{$\begin{array}{l}\text { Stereotype of Tamils as } \\
\text { malevolent }\end{array}$} & Map Condition & 1.487 & .324 & .022 & -.097 & -.021 & .899 \\
\hline & Percentage Estimate & - & - & - & -.042 & -.528 & .003 \\
\hline \multirow{2}{*}{$\begin{array}{l}\text { Stereotype of Tamils as } \\
\text { agentic }\end{array}$} & Map Condition & 2.067 & .477 & .001 & 1.852 & .428 & .015 \\
\hline & Percentage Estimate & - & - & - & -.006 & -.076 & .657 \\
\hline
\end{tabular}

Tamils along dimensions of malevolence and agency. The results on the manipulation check (estimated percentages of Sinhalese in the salient geographic region) allowed us to conduct some mediation analyses, examining the extent to which perceptions of numerical majority/minority status actually did account for the effects of the map manipulation. Two regression analyses were conducted for each of the key dependent variables for which a meaningful effect of the map manipulation was observed. One regression equation included just the map condition as a predictor (the Sri Lanka and India map conditions were numerically coded as 1 and 2, respectively). The second analysis included both the map condition and the estimated percentage of Sinhalese as predictors. If the effect of the map condition (in the one-predictor equation) is diminished when the percentage-estimate is also included as a predictor (in the two-predictor equation), this provides evidence that the perceived size of Sinhalese (relative to other ethnic groups) mediates the effect of the map manipulation.

Results from these regression analyses are summarized in Table 3 . These results indicate evidence of mediation on two of the three attitude items on which the map manipulation exerted a demonstrable effect: Support for the peace process (Sobel test $=2.76, p=.006$ ) and support for a semi-independent Eelam state (Sobel test $=2.11, p=.035$ ). In each case, the effect of the map manipulation was completely eliminated when the percentage-estimate measure was also included as a predictor. No mediation was observed on the item assessing support for a sovereign Eelam state. And although no mediation occurred on stereotypic perceptions of Tamil agency, there was clear evidence of mediation on stereotypic perceptions of Tamil malevolence: The effect of the map manipulation was eliminated entirely when the percentage-estimate measure was also included as a predictor $($ Sobel test $=2.82, p=.005$ ). 


\section{Discussion}

Given the pragmatic constraints on data collection, the methods used in this study were fairly crude and lacking in some elements of experimental rigor (e.g., it was not possible for the experimenter to be unaware of participants' experimental condition). Despite these limitations, the observed effects of the experimental manipulation were striking, and the specific patterns of results are difficult to attribute simply to deviations from experimental rigor. These results provide the first experimental evidence that, within a double-minority situation, a shift in geographical frame of reference influences outgroup stereotypes and conflictrelevant intergroup attitudes.

When presented with a geographical frame of reference in which their ingroup was outnumbered by Tamils, Sinhalese participants accessed a cultural stereotype of Tamils depicting Tamils as more malevolent—more angry, hostile, and cunning, more likely to have terrorist tendencies. Interestingly, the Tamil stereotype in this condition was not uniformly negative. At the same time that the geographical frame of reference facilitated the stereotypical perception of Tamils as malevolent, it also facilitated a stereotypical perception that Tamils are higher in the positively valued dimension of agency. Of course, in the context of malevolence, agency takes on a somewhat more sinister tone: Not only might Tamils intend harm, they also have the disposition and/or means to carry through with that intention. This combination of greater malevolence and greater agency connotes greater threat. Thus, compared to a context that implied their relative majority status, when the context implied their relative minority status, it appears that Sinhalese people were especially likely to perceive Tamils as a threat.

There was no symmetric effect on stereotypic perceptions of the ingroup. When the geographic frame of reference implied minority status for Sinhalese, the accessible stereotype of Sinhalese was more positive along the dimension of agency, but it was no different along the dimension of malevolence (e.g., Sinhalese did not judge their ingroup to be nicer). In general, the effect of the manipulation was observed primarily in perceptions of the outgroup, not so much in perceptions of the ingroup.

Consistent with its effects on the perception of Tamil threat, the geographical frame of reference also exerted an impact on several attitudes pertaining to the ongoing conflict between Sinhalese and Tamils. When the geographical context implied minority status for their ingroup, Sinhalese participants reported attitudes that were less generous toward Tamil interests in self-governed Eelam state. What is even more striking, perhaps, was the effect on attitudes toward the ongoing peace process. In general, since the ceasefire and negotiations began in 2002, Sinhalese Sri Lankans have been enthusiastic and optimistic about the peace process. This enthusiasm is evident in the very high mean ratings on this attitude item. Apparently, however, this high level of enthusiasm cannot be equated with unwavering support: When the geographical frame of reference implied minority 
status for their ingroup (and consequently a greater level of threat associated with the outgroup), Sinhalese participants were somewhat less supportive of the peace process. How should this effect be interpreted? It may reflect some greater sense that it is inappropriate to negotiate with Tamils (e.g., because they are more strongly judged to be terrorists). More likely, it reflects some greater concern that a negotiated peace settlement will give away too much of Sri Lanka to a Tamil state and thus compromise the interests of the Sinhalese people. In any case, it appears clear that a shift in geographical frame of reference can influence individuals' attitudes toward conflict resolution.

Just why did this shift in geographical frame of reference exert the effects that it did? We suspect it does so through its effects on the psychological experience of being in an outnumbered minority group: When Sinhalese feel outnumbered by Tamils, then they perceive Tamils to pose a greater threat and are less inclined toward conciliatory efforts at conflict-resolution.

Several alternative explanations might also be considered. Is it possible that the India map condition drew participants' attention to a potential threat from India, and that it was this nation-level threat (rather than the threat implied by the relative majority of Tamils) that precipitated changes in perceived stereotypes and attitudes? This seems unlikely. The Indian and Sri Lankan governments have cordial relations, and there is no immediate threat to Sri Lanka or to Sinhalese people from India. Another possibility is that the two experimental conditions drew participants' attention to two very different populations of Tamils: Perhaps the map that included India (but not the map of Sri Lanka) led participants to think specifically about Tamils in India, and their responses reflected the salience of Indian (rather than Sri Lankan) Tamils. This explanation seems unlikely as well. Sinhalese people do have distinct stereotypes about different Tamil populations (see Footnote 2), but those Tamils who are more closely linked to India are not stereotypically perceived to be more threatening and agentic; in fact, the opposite is true. The results from several mediation analyses also argue against the viability of these alternative explanations and in favor of an explanation based on perceived minority status. The effects of the manipulation on stereotypic perceptions of Tamil malevolence and on two of the attitude items (including support for the peace process) were entirely mediated by estimates of the relative size of the ingroup. These results provide evidence that geographical frame of reference influenced intergroup attitudes largely as the result of psychological processes unique to the double-minority situation.

This is just one study, of course, and it assessed stereotypes and attitudes from just one of the ethnic groups involved in the Sri Lankan conflict. A full accounting of this double-minority situation will require data that examines the effects of geographical frame of reference among Tamils as well. Sri Lanka offers just one of many examples of double-minority situations around the world. To more fully plumb the psychology of double-minorities - and its effects on intergroup conflict - it will be worthwhile to apply this kind of research strategy elsewhere too. 
In addition to providing one of the first empirical investigations of the psychology implicit in double-minority situations, these results also contribute in several ways to the broader psychological literature on intergroup prejudice.

These results contribute to a body of research that identifies links between specific kinds of dangers and specific kinds of prejudicial beliefs (Neuberg \& Cottrell, 2002; Schaller et al., 2003). It is well known that the realistic dangers associated with intergroup conflict precipitate prejudice (e.g., Campbell, 1965; Jackson, 1993). What is becoming increasingly clear, however, is that the perception of danger is highly subjective. Regardless of the real dangers posed by some outgroup, prejudicial responses to that outgroup are influenced by other variables that influence the extent to which individuals feel vulnerable to danger-and some of those variables (e.g., ambient darkness; Schaller et al., 2003) have nothing to do with intergroup conflict whatsoever. The results reported here implicate a link between perceived minority status and perceived vulnerability to the danger posed by an outgroup. In doing so, these results suggest that this perceived vulnerability is associated with a very specific kind of stereotype about that outgroup-a stereotype in which the outgroup is judged to be especially nasty, and especially capable.

It is noteworthy that the stereotype results showed the particular pattern that they did. Within the recent social psychological literature on stereotypes, there has been renewed interest in the specific contents of stereotypes (e.g., Schaller \& Conway, 2001). It is clear that not all negative stereotypes are created equal and that problematic prejudices may be associated with stereotypes that are not uniformly negative at all (Glick \& Fiske, 2001; Neuberg \& Cottrell, 2002). Many stereotypes are mixed: They contain elements that are both evaluatively positive and negative (Fiske et al., 2002). The results reported here represent evidence of an experimental manipulation leading to the activation of a stereotype that is simultaneously more negative (malevolent) on one dimension and more positive (capable) on another. Of course, this particular combination of traits would appear to demonize the outgroup—renders it stereotypically dangerous—even more than stereotypes that are uniformly negative in evaluative valence.

Another noteworthy aspect of these results is the fact that the effects of the experimental manipulation were observed primarily on stereotypical perceptions of the outgroup. The effect on ingroup stereotypes was more limited in scope. These results stand in contrast to the majority of laboratory-based research on intergroup biases, in which there is more evidence of ingroup enhancement than outgroup derogation (Brewer, 1999; Hewstone, Rubin, \& Willis, 2002). Of course, a considerable chunk of that experimental research has focused on intergroup perceptions among individuals in "minimal" groups that are artificially created for a short time within the limited context of an experimental session. In those minimal-group contexts, it may be natural for individuals to focus more on the characteristics of their new ingroup-and to manufacture reasons to like that ingroup-without any necessary concern for the outgroup. In many real-life cir- 
cumstances, however, the characteristics of an ingroup may be taken somewhat more for granted, while the potential characteristics of outgroups really matter. This may be the case especially within the context of intergroup conflict. In such contexts, the psychology of prejudice may be based not so much on the idealization of ingroups, but rather on the demonization of outgroups.

\section{Concluding Remarks}

It appears that members of minority groups are especially likely to engage in the kinds of "dangerous" thinking that propel groups toward conflict (Eidelson \& Eidelson, 2002). In many parts of the world, everyone-no matter what ethnic group they might belong to-can justifiably perceive their own group to be an outnumbered minority. The phenomenon may pose a psychological obstacle to conflict resolution. In presenting these results, we have deliberately attempted to highlight this potential obstacle.

However, our findings need not be framed in a pessimistic manner. Just as these results reveal that the adoption of the minority mindset leads to a greater demonization of the outgroup and a reduced enthusiasm for peaceful negotiation, these results also show that the adoption of the majority mindset is associated with a more gracious view of the outgroup and a greater enthusiasm for conciliatory peacemaking. Thus, while the double-minority demographic situation may indeed pose potential obstacles to conflict resolution, it also may offer a unique opportunity for intervention. To the extent that individuals-regardless of what ethnic group they might belong to-can be induced to perceive their group as the majority, then one of the many barriers to conflict resolution might just be breached.

\section{ACKNOWLEDGMENTS}

This research was supported by a grant from the Social Sciences and Humanities Research Council of Canada, by a sabbatical leave from the University of British Columbia, by the scholarly hospitality offered at the University of Peradeniya, and by travel funds provided by the Solomon Asch Center for Study of Ethnopolitical Conflict. For helpful comments, suggestions, and other forms of assistance, we thank Roy Eidelson, Sumanasiri Liyanage, Clark McCauley, Angela Pelpola, Paul Rozin, and Peter Suedfeld. Correspondence concerning this article should be addressed to Mark Schaller, Department of Psychology, University of British Columbia, 2136 West Mall, Vancouver BC V6T 1Z4, Canada. Email: schaller@psych.ubc.ca

\section{REFERENCES}

Bar-Tal, D. (2000). From intractable conflict through conflict resolution to reconciliation: Psychological analysis. Political Psychology, 21, 351-365. 
Bar-Tal, D. (2001). Why does fear override hope in societies engulfed by intractable conflict, as it does in the Israeli society. Political Psychology, 22, 601-627.

Brewer, M. B. (1999). The psychology of prejudice: Ingroup love or outgroup hate. Journal of Social Issues, 55, 429-444.

Brewer, M. B., Weber, J. G., \& Carini, B. (1995). Person memory in intergroup contexts: Categorization versus individuation. Journal of Personality and Social Psychology, 69, 29-40.

Campbell, D. T. (1965). Ethnocentric and other altruistic motives. In D. Levine (Ed.), Nebraska Symposium on Motivation (Vol. 13, pp. 283-311). Lincoln: University of Nebraska Press.

Chagnon, N. A. (1992). Yanomamö: The last days of Eden. New York: Harcourt Brace.

Chirot, D. (2001). Introduction. In D. Chirot \& M. E. P. Seligman (Eds.), Ethnopolitical warfare: Causes, consequences, and possible solutions (pp. 3-26). Washington: American Psychological Association.

Decker, S. H., \& Van Winkle, B. (1996). Life in the gang. New York: Cambridge University Press.

Devine, P. G., \& Elliot, A. J. (1995). Are racial stereotypes really fading? The Princeton Trilogy revisited. Personality and Social Psychology Bulletin, 21, 1139-1150.

Dodge, K. A. (1980). Social cognition and children's aggressive behavior. Child Development, 51, 162-170.

Eidelson, R. J., \& Eidelson, J. I. (2003). Dangerous ideas: Five beliefs that propel groups toward conflict. American Psychologist, 58, 192-192.

Fiske, S. T., Cuddy, A. J. C., Glick, P., \& Xu, J. (2002). A model of (often mixed) stereotype content: Competence and warmth respectively follow from perceived status and competition. Journal of Personality and Social Psychology, 82, 878-902.

Gigerenzer, G. (1998). Ecological intelligence: An adaptation for frequencies. In D. D. Cummins \& C. Allen (Eds.), The Evolution of Mind (pp. 9-29). New York: Oxford University Press.

Glick, P., \& Fiske, S. T. (2001). Ambivalent sexism. Advances in Experimental Social Psychology, 33, $115-188$.

Hewstone, M., Rubin, M., \& Willis, H. (2002). Intergroup bias. Annual Review of Psychology, 53, $575-604$

Hobbes, T. (1998). Leviathan. Oxford: Oxford University Press. (Original work published in 1651)

Insko, C. A., \& Schopler, J. (1998). Differential distrust of groups and individuals. In C. Sedikides, J. Schopler, \& C. A. Insko (Eds.), Intergroup cognition and intergroup behavior (pp. 75-107). Mahwah: Lawrence Erlbaum Associates.

Jackson, J. W. (1993). Realistic group conflict theory: A review and evaluation of the theoretical and empirical literature. The Psychological Record, 43, 395-414.

Mullen, B. (1991). Group composition, salience, and cognitive representations: The phenomenology of being in a group. Journal of Experimental Social Psychology, 27, 297-323.

Mullen, B., Brown, R., \& Smith, C. (1992). Ingroup bias as a function of salience, relevance, and status: An integration. European Journal of Social Psychology, 22, 102-122.

Neuberg, S. L., \& Cottrell, C. A. (2002). Intergroup emotions: A biocultural approach. In D. M. Mackie \& E. R. Smith (Eds.), From prejudice to intergroup relations: Differentiated reactions to social groups (pp. 265-283). Philadelphia: Psychology Press.

Roberchek, C. (1990). Motivations and material causes: On the explanation of conflict and war. In J. Haas (Ed.), The anthropology of war (pp. 56-76). Cambridge: Cambridge University Press.

Roberts, G. (1996). Why individual vigilance declines as group size increases. Animal Behaviour, 51, 1077-1086.

Rogers, J. D., Spencer, J., \& Uyangoda, J. (1998). Sri Lanka: Political violence and ethnic conflict. American Psychologist, 53, 771-777.

Rosnow, R. L., \& Rosenthal, R. (2003). Effect sizes for experimenting psychologists. Canadian Journal of Experimental Psychology, 57, 221-237. 
Ross, M. H. (1995). Psychocultural interpretation theory and peacemaking in ethnic conflicts. Political Psychology, 16, 523-544.

Rouhana, N. N., \& Bar-Tal, D. (1998). Psychological dynamics of intractable ethnonational conflicts: The Israeli-Palestinian Case. American Psychologist, 53, 761-770.

Rouhana, N. N., \& Fiske, S. T. (1995). Perception of power, threat, and conflict intensity in asymmetric intergroup conflict. Journal of Conflict Resolution, 39, 49-81.

Schaller, M., \& Conway, L. G., III (2001). From cognition to culture: The origins of stereotypes that really matter. In G. B. Moskowitz (Ed.), Cognitive social psychology: The Princeton symposium on the legacy and future of social cognition (pp. 163-176). Mahwah: Lawrence Erlbaum Associates.

Schaller, M., Park, J. H., \& Faulkner, J. (2003). Prehistoric dangers and contemporary prejudices. European Review of Social Psychology, 14, 105-137.

Simon, B. (1998). The self in minority-majority contexts. European Review of Social Psychology, 9, $1-30$.

Simon, B., \& Hamilton, D. L. (1994). Self-stereotyping and social context: The effects of relative in-group size and in-group status. Journal of Personality and Social Psychology, 66, 699-711.

Tajfel, H., \& Turner, J. C. (1986). The social identity theory of intergroup behavior. In S. Worchel \& W. G. Austin (Eds.), Psychology of intergroup relations (pp. 7-24). Chicago: Nelson-Hall.

Vasquez, J. A. (1992). The steps to war: Toward a scientific explanation of Correlates of War findings. In J. A. Vasquez \& M. T. Henehan (Eds.), The scientific study of peace and war: A text reader. New York: Lexington Books.

Wirtz, P., \& Wawra, M. (1986). Vigilance and group size in Homo sapiens. Ethology, 71, 283-286. 